\title{
EDUCAÇÃO MATEMÁTICA CRÍTICA NA EDUCAÇÃO PROFISSIONAL TÉCNICA DE NÍVEL MÉDIO: ALGUMAS REFLEXÕES SOBRE CURRÍCULO E ENSINO
}

\author{
KAMILA FERREIRA AUGUSTO \\ Instituto Federal do Espírito Santo \\ E-mail: kamila.peduerj@gmail.com

\section{LAURO ChAGAS E SÁ} \\ Instituto Federal do Espírito Santo \\ E-mail:proflaurosa@gmail.com
}

\section{ALEX JORDANE \\ Instituto Federal do Espírito Santo \\ E-mail: jordane@ifes.edu.br}

\section{RESUMO}

Em 2018, a Rede Federal de Educação Profissional, Científica e Tecnológica completou uma década de existência. Instituída a partir da Lei no 11.892/2008, a rede congrega diversas instituições que, juntas, ofertam 495.682 matrículas no nível médio (BRASIL, 2017), modalidade onde se deve articular o Ensino Médio com uma preparação para o mundo do trabalho. Nesse contexto, este ensaio teórico tem por objetivo compreender como as marcas da dualidade entre formação básica e formação profissional manifestam-se na Educação Matemática Crítica (EMC) e na Educação Profissional Técnica de Nível Médio (EPTNM), com vistas a entender similaridades e divergências entre a EPTNM e EMC, principalmente no que se refere ao currículo e ao ensino. A Matemática deve ser ensinada como ciência necessária para a resolução de problemas reais e para uma percepção crítica do mundo do trabalho.

\section{PALAVRAS-ChAVE:}

Educação Profissional e Tecnológica; Educação Matemática Crítica; Currículo; Ensino.

\section{CRITICAL MATHEMATICS EDUCATION IN TECHNICAL HIGH SCHOOL: NA APPROACH ON} CURRICULUM AND TEACHING

\begin{abstract}
In 2018, the Federal Network for Professional, Scientific and Technological Education completed a decade of existence. Established under Law No. 11,892/2008, the network brings together several institutions that, together, offer 495,682 enrollments at secondary level (BRASIL, 2017), a modality in which secondary education must be articulated with preparation for the world of work. In this context, this theoretical essay aims to understand how the marks of the duality between basic education and professional training are manifested in Critical Mathematics Education (CME) and in Middle Level Technical Professional Education (EPTNM), with a view to understanding similarities and


divergences between EPTNM and EMC, particularly with regard to curriculum and teaching. Mathematics must be taught as a necessary science for solving real problems and for a critical perception of the world of work.

\section{KEYWORDS:}

Professional and Technological Education; Critical Mathematics Education; Curriculum, Teaching.

\section{INTRODUÇÃO}

Em 2018, a Rede Federal de Educação Profissional, Científica e Tecnológica (RBEPCT) completou uma década de existência. Instituída a partir da Lei noㅡ 11.892/2008, a RBECT, também conhecida por Rede Federal, representa um marco na ampliação, interiorização e diversificação da Educação Profissional e Tecnológica no Brasil. Atualmente, participam dessa rede os Institutos Federais de Educação, Ciência e Tecnologia (IFs), a Universidade Tecnológica Federal do Paraná (UTFPR), os Centros Federais de Educação Tecnológica (CEFET-RJ e CEFET-MG), as Escolas Técnicas Vinculadas às Universidades Federais e o Colégio Pedro II, no estado do Rio de Janeiro (BRASIL, 2008). Tendo 495.682 matrículas no nível médio (BRASIL, 2017) e por envolver uma discussão em torno de um currículo que seja capaz de integrar o Ensino Médio com o Ensino Profissionalizante, identificamos esta modalidade como importante tema de pesquisa.

No contexto apresentado acima, este ensaio teórico configurou-se como um trabalho de conclusão do Curso de Pós-Graduação em Educação, ofertado no Instituto Federal do Espírito Santo, campus Cariacica. Adotamos como temática a Educação Matemática Crítica (EMC) na Educação Profissional Técnica de Nível Médio (EPTNM). Nesta pesquisa, propusemo-nos a atender ao objetivo de compreender, no plano teórico, a questão da dualidade no âmbito do ensino profissionalizante e, sob essa luz, entender similaridades e divergências entre a EPTNM e EMC, principalmente no que tange ao currículo e ao ensino.

\section{UMA BREVE INTRODUÇÃo À EdUCAÇÃo PROFISSIONAL E TECNOLÓGICA}


Com a Revolução Industrial, no século XVIII, a escola passou a ter função de transmissora de conhecimentos técnicos e científicos, oriundos das novas relações de trabalho. Segundo Manfredi (2002), saberes relacionados ao trabalho eram transmitidos por meio da observação, da prática e da repetição, com a utilização de ferramentas e instrumentos que auxiliassem o cotidiano das pessoas. Durante esses períodos, o trabalho era uma forma de sobrevivência, tendo caráter utilitarista e não de acumulação. Ou seja, esse tipo de educação era para a vida e não objetivava o lucro e a competição.

Para Frigotto (1999), o vínculo entre trabalho produtivo e educação foi alterado pela modernidade. O sistema capitalista passou a determinar os valores e as teorias, e as instituições - nesse sentido podemos incluir as escolas - passaram a produzir e reproduzir atitudes, ideologias e teorias que fazem com que o modelo de produção capitalista permaneça (FRIGOTTO, 1999 apud SENAC, 2007).

Escolas de agricultura, escolas de comércio, escolas de artes e ofícios, sociedades de estímulo em favor da indústria e das artes manuais, se instituem e se multiplicam [...] (MANACORDA, 1994, p. 286).

No Brasil, ainda que de forma não oficial, a formação para o trabalho surgiu ainda no período colonial, com os indígenas e as pessoas escravizadas. Com o descobrimento de ouro e com a criação das Casas de Fundição e de Moeda, havia a necessidade de uma educação especializada, destinada aos filhos de homens brancos. Nesse período a formação era feita no próprio ambiente de trabalho.

Ainda durante o descobrimento do ouro em Minas Gerais, foram criados os Centros de Aprendizagem de Ofícios nos Arsenais da Marinha no Brasil. Esses centros eram compostos por portugueses ou pessoas que eram recrutadas e que tivessem uma condição mínima de produzir. Durante esses períodos iniciais da história da Educação Profissional, havia um caráter também assistencialista da educação voltada para o trabalho (GARCIA, 2000). 
A história da Educação Profissional formal no Brasil teve início oficial somente no ano de 1909, quando o Decreto-lei no 7.566, de 23 de setembro de 1909 foi sancionado pelo Presidente da República Nilo Peçanha. Esse decreto-lei passou a instituir a Educação Profissional como meio de capacitação para atender o desenvolvimento industrial no país. Foi nesse contexto que as Escolas de Aprendizes Artífices surgiram. As Escolas de Aprendizes Artífices tinham caráter assistencialista, eram destinadas às camadas mais pobres da população. Essas escolas ministravam cursos de tornearia, mecânica e eletricidade, carpintaria, entre outros, o que nos remete às Workhouses, que tiveram início no século XVII, na Inglaterra, com objetivo de oferecer assistência, educação elementar e formação para o trabalho (PINTO, 2015).

Em 1937, foi criada a Lei no 378, que transformou as Escolas de Aprendizes e Artífices em Liceus Profissionais. De 1930 a 1945, com a industrialização no país, as Escolas de Artífices foram transformadas em escolas industriais e técnicas, com formação profissional que equivalia ao ensino médio. Foi criado no Liceu, localizado no Rio de Janeiro, o Curso Comercial, que tinha como objetivo formar profissionais capacitados para trabalhar no comércio. As disciplinas relacionadas à Matemática oferecidas no primeiro ano do Curso Comercial eram de Desenho Linear Geométrico e Aritmética. A Matemática ensinada no Curso Comercial do Liceu teve como função a transformação social, pois a aritmética representava a disciplina que servia de base para todos os conteúdos ensinados posteriormente. Além disso, o curso serviu também para qualificar as pessoas com menor poder aquisitivo. A criação do Curso Comercial culminou em uma nova função social para o ensino da Matemática.

A partir da década de 60 do último século, com as indústrias automobilísticas, as escolas técnicas passaram a se chamar Escolas Técnicas Federais e, em 1994, a Lei no 8.984 instituiu o Sistema Nacional de Educação Tecnológica, transformando essas escolas em Centros Federais de Educação Tecnológica (Cefet). O fato é que a década 
de 30 teve grande importância na história da Educação Profissional no Brasil, assim como a década de 40, com o surgimento do Sistema S, conjunto de organizações voltadas para o treinamento profissional, assistência social, consultoria, pesquisa e assistência técnica, os quais, além de terem seu nome iniciado com a letra S (Sesi, Sesc, Senai, Senac, Senar, Sebrae), têm suas origens e características semelhantes.

No ano de 2004, o Decreto 5.154 revogou o Decreto 2.208/97, que regulamentava a Educação Profissional, e passou a regular essa modalidade de ensino (BRASIL, 2004). Esse decreto permitiu a integração do ensino regular com a Educação Profissional e continuou mantendo a possibilidade de segmentação dos cursos. Já durante o governo Lula, houve a possibilidade de construir o projeto pedagógico baseado na concepção de formação integral, porém ainda se mantendo a separação entre o ensino profissional e propedêutico, devido à influência de grupos que possuem pensamentos diferentes no Congresso Nacional.

Mais recentemente, com o objetivo de planejar o futuro da Educação, foi promulgado o Plano Nacional de Educação (PNE), lei ordinária com vigência de dez anos a partir de 2014, prevista no artigo 214 da Constituição. Com foco na EPTNM, a Meta 11 do PNE estabeleceu que as matrículas de Educação Profissional deverão ser triplicadas até 2024. Esse número corresponde ao número de matrículas do ano de aprovação do PNE.

Frente ao que foi apresentado, percebemos que resistências e memórias de uma educação com foco na utilidade dos conhecimentos fazem parte da história da EPTNM. Em face de tantas mudanças ao longo de anos, percebemos que a EPTNM caminha para uma formação integral de trabalhadores. E como a Matemática pode contribuir para esse movimento? Nessa perspectiva, apresentamos a proposta da Educação Matemática Crítica. 


\section{A EdUCAÇÃo MATEMÁTICA CRÍTICA}

Um dos precursores da EMC é Ole Skovsmose que, no início de 1970, período em que muitos países viviam sob regimes políticos autoritários, começou suas tentativas de formular a teoria da EMC, quando a educação crítica ainda não se interessava pela Matemática.

Foi durante os estudos do doutorado que Skovsmose dedicou-se de forma mais sistemática ao tema. O autor teve como influência a Educação crítica, sendo a leitura do livro Pedagogia do Oprimido (FREIRE, 1987) de grande importância para o desenvolvimento de suas pesquisas. O maior desafio para o pesquisador dinamarquês, segundo seus escritos, foi entender como a Educação Matemática poderia servir à emancipação, considerando que a Matemática é, a priori, constituída por interesses técnicos.

Para Skovsmose (2014), a Matemática representava a objetividade e a neutralidade, do ponto de vista da modernidade, supervalorizada quando se trata de Ciência e como superagente quando se trata de tecnologia e progresso. Para o autor, na perspectiva da EMC, faz-se necessário um olhar atento sobre a importância da Matemática, pois, dependendo da forma como é utilizada, ela pode ser arriscada, servindo para outra função que não o progresso. Mais ainda, acredita-se que seja necessário pensar na Matemática como ferramenta de transformação da realidade, para a justiça social, que proporcione leitura crítica de um mundo matematizado, em que a Matemática é utilizada desde as compras no supermercado até na medicina, buscando desenvolver a capacidade de interpretação do mundo, estruturado por números e figuras, e à capacidade de atuar nesse mundo.

Tendo como entendimento que a escola cria sentido à medida em que proporciona condições para a resolução de problemas sociais reais, podemos perceber que a prática cotidiana da Matemática escolar, por vezes, se afasta da realidade. Isto, 
porque se observarmos os exercícios solicitados nas escolas, perceberemos que estes se materializam em ordens para que simplifiquem expressões, resolvam equações e "encontrem o x". Essa obediência, imposta por esses tipos de exercícios, revela-se como uma condição necessária para a inserção dos jovens e adultos no mundo do trabalho, no qual o papel da Matemática seria ajudar a reforçar essa condição, em que é preciso ser obediente e não questionar as demandas do trabalho.

A educação matemática pode potencializar de diversas formas. Pode ser potencializadora para uns despotencializadora para outros. Potencializadora para aqueles que buscam adquirir competências valorizadas pelo mercado de trabalho. E despotencializadora na medida em que reforça um comportamento de adequação e obediência a regras. (SKOVSMOSE, 2014, n.p).

Os exercícios matemáticos no formato de ordens podem ser substituídos por atividades relacionadas ao contexto social dos estudantes, tornando-se, assim, mais agradáveis e sua compreensão mais acessível. Para isso, é importante que o docente conheça o contexto a ser problematizado, para que possa estabelecer a mediação das aulas, com foco no desenvolvimento de competências relacionadas às ocupações do mundo do trabalho de maneira crítica. A compreensão dos conhecimentos e a aquisição das técnicas é crucial para a repercussão do aprendizado na vida social dos alunos.

\section{EducaÇÃo Matemática Crítica na EducaÇão Profissional téCnICA de NÍVEL MÉdIO}

Nesta seção, buscaremos as possíveis conexões entre EPTNM e a EMC a partir de duas perspectivas: uma centrada no currículo e a outra direcionada, mais especificamente, ao ensino.

\subsection{REFLEXões SOBRE o CURRÍ́CULO}

O currículo formal pode ser entendido como experiências de aprendizagem, conteúdos, atividades planejadas e sistematizadas (TANNER; TANNER, 1975). Definir o 
que é útil, para quê e para quem e quais conteúdos e objetivos são mais úteis e como devem ser organizados certamente não é uma tarefa fácil para os sujeitos envolvidos na construção de currículos.

Tais características curriculares da EMC se aproximam da EPTNM à medida em que as demandas sobre a escola crescem diante das transformações no mundo do trabalho e no comportamento das pessoas e que, por isso, exige que sujeitos envolvidos na formação de trabalhadores reflitam sobre as transformações na sociedade.

Se pela formação geral as pessoas adquirem conhecimentos que permitam compreender a realidade, na formação profissional o conhecimento científico adquire, para o trabalhador, o sentido de força produtiva, traduzindo-se em técnicas e procedimentos, a partir da compreensão dos conceitos científicos e tecnológicos básicos que o possibilitarão à atuação autônoma e consciente na dinâmica econômica da sociedade (RAMOS, 2014, p. 92).

Os elementos que caracterizam o currículo da EPTNM são pré-estabelecidos pelas demandas do trabalho, que passam por constantes mudanças e encontram no trabalho, em seu sentido mais amplo, um instrumento de transformação social, diferentemente da EMC, que utiliza como instrumento de transformação especificamente uma Ciência. Como exemplo de elemento que caracteriza a EPTNM temos a tecnologia, que faz com que a essa modalidade de ensino assuma-se como instrumento de inovação e transformação das atividades econômicas, podendo contribuir para a formação do cidadão e o desenvolvimento do país (BASTOS, 1998).

Conforme vimos, na EPTNM e na EMC, podemos considerar a reflexão diante das transformações da sociedade um importante elemento de interseção. Esse cenário de formação para o emprego é modificado e aproxima-se da EMC quando a EPTNM assume o trabalho como princípio educativo, que contribui para que sujeitos sejam autônomos, compreendam-se no mundo e atuem por meio do trabalho, 
transformando a natureza em função das necessidades da humanidade, sem desconsiderar a relevância de sua preservação.

A matemática é uma parte integrante de diferentes modos de formatação de nosso ambiente e de nossa tecnonatureza, mas tal formatação não é certeza de uma melhoria automática das circunstâncias. A tecnologia causa impacto em todos os aspectos da vida. Ela traz mudanças, mas a tecnonatureza não tem evoluído em nenhum critério de progresso, e não há nada de natural a respeito desse crescimento (SKOVSMOSE, 2014, n.p).

Para além da formação para o emprego, é importante que a educação prepare também para a cidadania crítica, ou seja, prepare para uma vida política e não se limite ao desenvolvimento de competências profissionais, definidas pelas Diretrizes Curriculares Nacionais para a EPTNM, como princípio orientador da organização curricular e da prática pedagógica na Educação Profissional. De acordo com o art. 6으 da Resolução CNE no 4, a competência profissional é entendida como "a capacidade de mobilizar, articular e colocar em ação valores, conhecimentos e habilidades necessárias ao desempenho eficiente e eficaz de atividades requeridas pela natureza do trabalho".

A partir do que foi exposto, percebemos que é necessário um olhar reflexivo para a Matemática. Por isso, há uma exigência da visão ética referente a todos os processos sociais, em especial àqueles dos quais a Matemática faz parte. Skovsmose (2006) faz uma distinção entre três tipos de conhecer na matemática: conhecer matemático, conhecer tecnológico e conhecer reflexivo. O primeiro relaciona-se com a educação tradicional; o segundo, com a construção de modelos, assim como a aplicação da Matemática; e o terceiro tipo, com as consequências da tecnologia. A partir dessa tipologia de Skovsmose (2006), percebemos, no currículo da EPTNM, o conhecer matemático e o tecnológico, sobretudo quando se trata de competências profissionais. Pensando na leitura crítica de mundo, os conhecimentos matemáticos podem ser utilizados em diferentes eixos tecnológicos. 
As linhas de frente da Educação Matemática têm hoje um cuidado crescente com o aspecto sociocultural da abordagem Matemática. Defendem a necessidade de contextualizar o conhecimento matemático a ser transmitido, buscar suas origens, acompanhar sua evolução, explicitar sua finalidade ou seu papel na interpretação e na transformação da realidade do aluno. É claro que não se quer negar a importância da compreensão, nem tampouco desprezar a aquisição de técnicas, mas busca-se ampliar a repercussão que o aprendizado daquele conhecimento possa ter na vida social, nas opções, na produção e nos projetos de quem aprende (FONSECA, 1995, p. 46).

Existe uma ideia da Matemática como um sistema perfeito, puro, como se a ela estivesse acima de tudo e fosse inquestionável, totalmente livre da influência humana. Esse entendimento, por sua vez, colabora com a opressão na sociedade, pois entendese que a matemática não é influenciada por nenhum tipo de interesse social ou político, quando, na verdade, ela só pode ser "perfeita" quando o contexto é adequado. Deve-se buscar:

[...] uma educação matemática dos estudantes que não vise apenas instrumentá-los matematicamente, mas que também proporcione sua atuação crítica na sociedade, por meio desse conhecimento matemático, o que é uma forma de proporcionar sua emancipação como cidadãos (ARAÚJO, 2009, p. 55).

Entendemos que as mudanças na educação, nesse caso no currículo escolar, são lentas. Assim, para viabilizar as reformulações curriculares, as escolas poderiam se organizar em grupos de trabalhos, compostos principalmente por docentes, com papel reflexivo sobre o próprio fazer profissional. O professor não deve sozinho decidir e prescrever sua ementa, mas, através de um trabalho colaborativo, pensar sobre como estabelecer estratégias para aproximar os meios e os fins do currículo. Mas como isso reverbera no ensino? É o que tentaremos responder na próxima seção deste ensaio.

\subsection{REFLEXÕES SOBRE O ENSINO}

No que tange ao ensino, durante muitos anos a Matemática foi ensinada na EPTNM de forma restrita aos requisitos exigidos pelas ocupações do trabalho, baseado no paradigma verdadeiro-falso utilizado pelas escolas (PINTO, 2015). Na sociedade 
atual, devemos ter como preocupação proporcionar aos estudantes, futuros trabalhadores, a compreensão das dinâmicas existentes no mundo. Consequentemente, possibilitar uma atuação autônoma desse sujeito que tem o trabalho como força produtiva.

Em se tratando do ensino, na perspectiva da EMC, entendemos que este se aproxima da EPTNM ao ser direcionada para a realidade social dos alunos, apoiados na pesquisa, na reflexão, no levantamento de hipóteses e em problemas reais.

Trabalhos com projetos e abordagens temáticas têm sido considerados uma resposta emblemática aos desafios educacionais lançados pela educação crítica. [...] Considero que uma nova educação matemática crítica deve buscar possibilidades educacionais (SKOVSMOSE, 2008, p. 13)

Na EMC, as dinâmicas presentes na sociedade são trazidas para a escola, o que, de certa forma, converge com a EPTNM quando essa se preocupa em possibilitar que os estudantes compreendam a realidade. Isso, porque limitar o ensino na EPTNM ao "aprender fazendo" (RAMOS, 2014) e formar para o exercício do trabalho é inadequado, já que o trabalho, a ciência, a tecnologia e a cultura são indissociáveis e, por isso, não devemos reduzir a formação para o mercado de trabalho.

É comum aos elaboradores de currículo da EPTNM o questionamento sobre a aplicabilidade do conhecimento, carregando uma característica utilitarista dos saberes. Nessa perspectiva, a Matemática operaria conforme sua relevância, seja ela existente ou ainda enquanto mero potencial. Por outro lado, na EMC, compreendemos a Matemática como conhecimento imprescindível para o mundo do trabalho. Podemos entender a educação matemática como uma ferramenta para reorganizar a sociedade, no lugar de um conhecimento com foco na reprodução. Em relação a esse aspecto, Alves e Matos (2008), apoiados em Ernest (2001), afirmam que:

a ideia do conhecimento matemático válido por si só, visto como intocável pelo desenvolvimento social e histórico, puro, abstracto e livre de valores culturais, dá lugar a uma perspectiva onde a matemática deixa de ser inquestionável e onde deixa de ser vista como um produto 'branco' e 
europeu, reconhecendo-se os múltiplos contributos vindos de diferentes partes do mundo (ALVES; MATOS, 2008, p. 712).

Nos aspectos metodológicos, ensinar sob a perspectiva de problemas é algo relativamente frequente na EPTNM, já que essa modalidade está diretamente ligada ao mundo do trabalho. Quando trazemos para o contexto da EMC, o problema a ser investigado deve ser relevante para os estudantes, de forma a serem próximos de suas experiências e da teoria. Nesse sentido, o docente precisa sair da zona de conforto e correr riscos junto aos estudantes em cenários de investigações.

Crenças e visões de mundo estabelecidas, ao serem confrontadas e desafiadas por uma investigação, deveriam ser passíveis de mudanças e aperfeiçoamentos. Um diálogo é algo imprevisível. Não há respostas prontas, conhecimentos de antemão, para os problemas. Elas surgem através de um processo compartilhado de curiosa investigação e reflexão coletiva, com o propósito de obter conhecimento. Impresivisibilidade significa o desafio de experimentar novas possibilidades [...]. (ALRO; SKOVSMOSE, 2006, p. 127128)

Ou seja, na perspectiva da EMC, o ensino não deve servir como reprodução de relações sociais e de poder, mas servir para manter um papel ativo no combate de disparidades sociais. Por isso, é importante que as relações nos espaços pedagógicos sejam horizontais e, portanto, todo o processo educacional deve ser norteado pelo diálogo.

Através do diálogo, o professor-dos-estudantes e os estudantes-do-professor se desfazem e um novo termo emerge; professor-estudante com estudantesprofessores. O professor não é mais meramente o que ensina, mas alguém a quem também se ensina no diálogo com os estudantes, os quais, por sua vez, enquanto estão ensinando, também aprendem. Eles se tornam conjuntamente responsáveis por um processo no qual todos crescem (FREIRE, 1972, p.53).

Pelo que foi apresentado, percebemos, então, que o ambiente de ensino deve ser favorável à investigação, de forma que ofereça suporte necessário ao trabalho investigativo de alunos e professores. Também deve ser propício para que os alunos desenvolvam capacidades matemáticas e sejam capazes de formularem questões e procurarem explicações para os problemas nos quais a Matemática esteja envolvida. 


\section{CONSIDERAÇÕES FINAIS}

As discussões promovidas ao longo deste artigo levaram-nos a entender que as marcas que traduzem dualidades entre formação matemática e formação técnica manifestam-se por meio do cumprimento de ordens expressas em exercícios matemáticos descontextualizados. Acreditamos que isso conduz a uma falta de sentido em aprender uma Matemática necessária para a resolução de problemas reais e para uma percepção crítica do mundo do trabalho.

Percebemos que a EPTNM objetiva atender a demandas do mundo do trabalho e que, por sua vez, é realizada utilizando estratégias didáticas, como estudos de casos e situações problemas, o que pode suscitar em uma aproximação com a EMC ou até mesmo uma complementação. No entanto, o trabalho, sob uma perspectiva que busca a acumulação de capital, faz com que a escola reproduza atitudes que contribuem para a permanência de injustiças sociais, o que lamentavelmente faz com que o ensino da Matemática não contribua para uma educação de fato emancipadora.

De acordo com as discussões de Ole Skovsmose e seu grupo da EMC, no momento em que o ensino de Matemática é baseado em problemas com referência à realidade ou à semi-realidade, a Matemática pode aproximar-se da Educação Crítica. Ainda assim, por questões relacionadas a diversos fatores, potenciais oportunidades não são aproveitadas adequadamente na sala de aula. Neste trabalho, reforçamos como a contextualização, com situações reais ou com referência à realidade, pode resultar em transformações na sociedade com a colaboração de docentes e alunos, principalmente na EPTNM. 


\section{REFERÊNCIAS}

ARAÚJO, J. de L. Uma Abordagem sociocrítica da modelagem matemática: A perspectiva da educação matemática crítica. Revista de Educação em Ciência e Tecnologia, Florianópolis, v.2, n.2, p. 55-68, jul. 2009.

ALVES, A. S.; MATOS, J. F. Educação Matemática Crítica na Escola. In: SEMINÁRIO DE INVESTIGAÇÃO EM EDUCAÇÃO MATEMÁTICA, 19., 2008, Badajoz. Anais... Badajoz, 2008. p. 709-716.

BASTOS, J. A. A educação tecnológica: conceitos e perspectivas. In: BASTOS, J.A. Tecnologia e interação. Curitiba: Cefet-PR, 1998. p. 11-30.

BRASIL. Casa Civil. Lei № 9.394, de 20 de dezembro de 1996. Estabelece as diretrizes e bases da educação nacional. Disponível em: <http://www.planalto.gov.br/ccivil_03/LEIS/L9394.htm>. Acesso em: 20 nov. 2018.

BRASIL. Decreto-Lei no 5.154, de 23 de julho de 2004. Regulamenta o § 20 do art. 36 e os arts. 39 a 41 da Lei no 9.394, de 20 de dezembro de 1996, que estabelece as diretrizes e bases da educação nacional, e dá outras providências. Disponível em: <http://www.planalto.gov.br/ccivil_03/_Ato2004-2006/2004/Decreto/D5154.htm>. Acesso em: 20 nov. 2018.

BRASIL. Lei no 11.892, de 29 de dezembro de 2008. Institui a Rede Federal de Educação Profissional, Científica e Tecnológica, cria os Institutos Federais de Educação, Ciência e Tecnologia, e dá outras providências. Disponível em: <http://www.planalto.gov.br/ccivil_03/_Ato2007-2010/2008/Lei/L11892.htm>. Acesso em: 01 dez. 2018.

BRASIL. Conselho Nacional de Educação. Resolução CNE/CEB no 4, de 08 de dezembro de 1999. Institui as Diretrizes Curriculares Nacionais para a Educação Profissional de Nível Técnico. Diário Oficial da União, Brasília, 8 dez. 1999. Disponível em <http://portal.mec.gov.br/dmdocuments/rceb004_99.pdf>. Acesso em: 31 mar. 2019.

BRASIL. Conselho Nacional de Educação. Resolução CNE/CEB no 6, de 20 de setembro de 2012. Define Diretrizes Curriculares Nacionais para a Educação Profissional Técnica de Nível Médio. Disponível em $<$ http://portal.mec.gov.br/index.php?option=com_docman\&view=download\&alias=1 1663-rceb006-12-pdf\&category_slug=setembro-2012-pdf\&ltemid=30192>. Acesso em: 31 mar. 2019.

BRASIL. Ministério da Educação. Censo escolar da educação básica 2016: Notas Estatísticas. 2017.

FONSECA, M. C. F. R. Por que ensinar Matemática. Presença Pedagógica, Belo Horizonte, v.1, n. 6, mar/abril, 1995. 
FREIRE, P. Pedagogia do oprimido. São Paulo: Paz e Terra, 1972.

FRIGOTTO, G. A produtividade da escola improdutiva. São Paulo: Cortez, 1999.

GARCIA, S. R. de O. O fio da história: a gênese da formação profissional no Brasil. In: . (Org.). Trabalho e Crítica. São Leopoldo: Ed. UNISINOS, 2000. Disponível em: <http://www.anped.org.br/reunioes/23/textos/0904t.PDF>. Acesso em: 31 mar. 2019.

LOPES, A. C.; MACEDO, E. Teorias de currículo. São Paulo: Cortez, 2011.

MANACORDA, M. A. História da Educação: da Antiguidade aos nossos dias. 4. ed. São Paulo: Cortez, 1994.

MANFREDI, S. M. Educação Profissional no Brasil. São Paulo: Cortez, 2002.

PINTO, A. H. Educação Matemática e Educação Profissional: elos de uma histórica relação. 1. ed. Curitiba-PR: Appris, 2015.

RAMOS, M. História e política da Educação Profissional. Curitiba: Instituto Federal do Paraná, 2014.

SENAC. A Educação Profissional no contexto da educação. Disponível em: <http://www.senac.br/conheca/referenciais/ref2.htm>. Acesso em: 31 mar. 2019.

SKOVSMOSE, O. Educação Matemática Crítica: A questão da democracia. 3a ed. Campinas: Papirus, 2006.

SKOVSMOSE, O. Desafios da reflexão em Educação Matemática Crítica. Campinas, SP: Papirus. 2008.

SKOVSMOSE, O. Um convite à Educação Matemática Crítica. Campinas-SP: Papirus, 2014.

TANNER, D.; TANNER, L. Curriculum development. New York: Macmillam, 1975. 